briefly mentioned. The picture presented, of an assembly of molecules with well-defined positions and velocities, is a classical one, and quantum theoretical considerations are treated only in a final chapter. One feels that this important aspect of the problem could profitably have been discussed at greater length.

The large number of complicated mathematical equations are all well set out and concisely expressed in a specialized notation which is easy to use after a little practice. But the balance struck between the mathematical development of the argument and the physical description of the results does not always leave the reader with a very clear picture of their precise significance for real fluids. Some of the intermediate steps in mathematical arguments which could not be given fully might well have given place to more discussion, with more frequent references to original papers. The book is not an easy one to read, which is no doubt largely due to the inherent difficulty of the subject. It should be very stimulating to the serious student.

J. G. OLDROYD

\section{IMPERFECTIONS IN METALS}

Imperfections in Nearly Perfect Crystals Symposium held at Pocono Manor, October 12-14, 1950. Editorial Committee: W. Shockley (chairman), J. H. Hollomon, R. Maurer, F. Seitz. Sponsored by the Committee on Solids, Division of Physical Sciences, the National Research Council. Pp. xii + 490. (New York: John Wiley and Sons, Inc.; London: Chapman and Hall, Ltd., 1952.) 60s. net.

7 HERE can be only one opinion about this book - that it is, and will for some time remain, a standard work of reference on the subject of imperfections in crystals. It is a report on a conference held in the United States, and, as the list of names of the editorial committee suggests, a galaxy of talent has contributed to it. The list of contributors -twenty in all-is too extensive to be given here, but the standard is exemplified by the first chapter, in which Prof. F. Seitz gives an eminently readable general account of crystal imperfections. He introduces several terms, such as phonons and excitons, which will be new to many people but which will probably come into common use in the future.

The book is divided into four parts : the nature of imperfections; the role of imperfections in deformation; diffusion and related phenomena; and the properties and effects of external and internal surfaces. Seitz's chapter is by far the longest in the book; the rest of the contributors "dot the i's and cross the t's", as it were. As is usual in a symposium, the mode of treatment varies greatly ; some chapters are descriptive and others are severely mathematical, but all bear the stamp of authority. The student of theoretical metallurgy is certain to find the book extremely valuable.

For this reason, I would suggest that the title of the book is unwise; it is pedantically correct, but is nevertheless misleading. In the first place, the practical aspects of the work described are almost entirely concerned with metals. It is true that the first chapter is written in general terms, and that there are two other chapters concerned with nonmetals, but practically all the other authors make it quite clear that they considered the conference to be one on the metallic state. Secondly, why is the term "nearly perfect" included in the title? Is it usual, for example, to consider a cold-worked powder as nearly perfectly crystalline? Possibly it is nearly perfect, since the distortion rarely exceeds $0 \cdot 1$ per cent, but I maintain that the title of the book would not suggest immediately that such a subject is included.

This is an important point. The first contact the potential reader has with a book is in reading the title, and it would be a great pity if the title of this book were to cause it to be overlooked by the theoretical metallurgists of countries outside the United States.

H. LIPSON

\section{UNUSED LAND AND HUNGRY PEOPLE}

\section{Our Undeveloped World}

By L. Dudley Stamp. Pp. 187. (London: Faber and Faber, Ltd., 1953.) 18s. net.

THE world's land surface is about 33 thousand million acres; only about 3 thousand million are cultivated : as the world's population is about 2.4 thousand million, this allows only 1.4 acres per head for both food and cash crops. If all this land were devoted to food crops and all gave English yields, a fairly satisfactory dietary would result; but some of the land is used for cash crops and most of it gives yields much lower than ours. Another 51 thousand million acres provides some sort of grazing and yields some meat and milk; but large numbers of the world's sheep and cattle furnish neither, and give only wool, hides and tallow. The world's average dietary remains poor.

It has long been the business of agricultural science and practice to seek ways of pushing the area of cultivated land into the grass regions or into the land wholly unused; the fact that 92 per cent of the land surface is uncultivated while millions of people go hungry has been a perpetual challenge that could not be ignored. Prof. Stamp has long studied these unused lands, and also those only partly developed : he summarized his results in the Patten Foundation Lectures given at the University of Indiana in 1950 which were published early in 1952 jointly by the Indiana University Press and the American Geographical Society, and are now re-issued with some additions and rearrangement in this British edition.

He begins with a discussion of the world population, its distribution and rate of increase in the different regions-pointing out incidentally that the increase is most rapid in the Americas, the crude birth-rate of the United States in 1947 being as high as that in India. He then gives a lucid account of the different regions of the world with special reference to their possible value for food production.

The wet tropical regions, in spite of the luxuriance of their forest vegetation, are not really very suitable : their soils are poor and lateritic; the native method of utilization is by shifting cultivation, which served so long as populations were low but is inapplicable when the numbers rise and increase the pressure on the land. As yet no very satisfactory substitute has been worked out, nor have the food crops been properly integrated with the cash crops, and until both sets of problems are solved there can be little further expansion of food production there. In the equatorial lands "the maps suggest that there are at 